\title{
Does prestige lead to discrimination in the labor market? Evidence from a labor market field experiment in three countries
}

\author{
Georgiana Mihut
}

Email: georgiana.g.mihut@gmail.com

ORCID: 0000-0001-6500-5417

\begin{abstract}
Do employers prioritize the name of the university someone graduated from above an applicant's skills in the employment process? 2,400 fictitious applications were submitted to IT and accounting job openings in three countries: United States, United Kingdom, and Australia. The resumes belonged to fictitious citizens, both female and male, that have attended universities of varying prestige in the respective countries. For each sector of the labor market, two resumes were designed. One resume had a high skills match with the generic requirements of entry level jobs in each sector. A second resume had a low skills match with the same requirements. For each country, one high-ranked university and one non-high-ranked university were selected to signal prestige. The name of the university the applicant graduated from and their sex were randomly assigned on otherwise identical resumes. This study distinguished between the effects of human capital from the effect of the name of the graduating university - while controlling for networking effects-in the hiring process. Human capital was statistically significant in predicting callbacks. Applications in the high skills match condition were $79 \%$ more likely to receive a callback than applications in the low skills match condition. The prestige condition, the interaction between university prestige and match, and sex were not statistically significant. These findings suggest that human capital, and not university prestige, predicts recruitment outcomes for applicants with a bachelor's degree only in skill intensive sectors of the labor market.
\end{abstract}

Keywords: university prestige, experimental design, higher education stratification, labor market, human capital

This is an Author's Original Manuscript of an article published by Taylor \& Francis in Studies in Higher Education on 5 January 2021, available at https://www.tandfonline.com/doi/full/10.1080/03075079.2020.1870949 


\section{Introduction}

Evidence that graduates of prestigious universities have added benefits in the labor market is systematically viewed as a reflection of merit, rather than discrimination. This is despite findings that admission at these institutions is not entirely meritocratic (Arcidiacono, Kinsler, and Ransom, 2019; Espenshade, Chung, and Walling, 2004; Golden 2007) and that students of disadvantaged background are less likely to be admitted to (Posselt 2016), attend (McKinley and Brayboy 2004; Tett 2004) and complete (Roksa 2011) an elite post-secondary degree program across international contexts (FengLiang and Morgan 2008; Hao, Hu, and Lo 2014; Reay, Crozier, and Clayton 2009). Using a field experiment of the labor market, I test if the effect of university prestige goes beyond meritocratic ideals and into the realm of discrimination. Absent of networking effects_-does prestige matter above relevant skills for jobs where skills matter?

Academic literature suggests that graduating from a prestigious university has a wide array of monetary and nonmonetary benefits for individuals (Black and Smith 2004; 2006; Brewer, Eide, and Ehrenber 1999; Long 2008; 2010; Long, Allison, and McGinnis 1979; Monks 2000; Morley and Aynsley 2007; Rivera 2015). Hoekstra (2009) suggests that graduating from the flagship state institution in the US yields 20 percent higher earnings for graduates. Rivera (2015) amply documents that employers make use of reverse recruitment practices in which the prestige of the institution is a necessary albert not a sufficient criterion to obtain a job at select companies. Overall, the academic literature supports the existence of a strong correlation between university prestige and life earnings, without having offered casual inferences on the effects of prestige in the labor market. By using an experimental design, this research tests the causal link between university prestige and labor market outcomes - a contribution to the primarily correlational literature on this question. 
Academic literature also suggests that women benefit less from attending a prestigious institution than men (Long 2008). Black and Smith (2004) find that attending more prestigious colleges increases wages by 11 or 12 percent for men and by about 7.5 percent for women. Monks (2000) illustrates a mixed relationship between sex and the rate of return in earnings for college graduates. While female graduates of specialized institutions earned more than males, the relation reversed for males attending a graduate degree-granting or a research university. My study tests if the effect of university prestige in skill-intensive sectors of the labor market varies by sex.

A field experiment of the labor market requires the submission of fictitious applications to job openings and measuring the callback rate. Two field experiments of the labor market have previously been conducted with the purpose of unpacking a potential causal link between university prestige and labor market outcomes. Gaddis (2013) conducted a field experiment of the labor market that analyzed the effects of university selectivity (prestige), sex, and race in the US. Gaddis submitted paired fictitious applications to 1,008 job openings in three metropolitan regions in the US. His result suggests a preference for applicants from prestigious institutions and the presence of race-based discrimination in the labor market. In Gaddis's study, applications in the high prestige condition (10\% callback rate) received an overall callback rate that was 1.6 times higher than applications in the low prestige condition (6.4\% callback rate). Jackson (2009) conducted a field experiment of the labor market in the UK. She included university prestige as an experimental condition-alongside degree level, class signifiers, and sex. Jackson submitted job applications to 2,560 UK based companies. The study received an overall small callback rate across all condition, and hence no inferential analysis was possible. However, she documented a higher callback rate for her high-ranked university $(2.1 \%)$ than her low-ranked university $(0.8 \%)$. Female 
applicants received a marginally higher callback rate than male applicants. My article complements existent studies by including controls for skill match within relevant sectors of the labor market — as a means to test for potential discrimination — and by testing the effects of prestige in three countries: US, UK, and Australia.

Under the meritocratic narrative, the assumed explanation for the added benefits in the labor market for graduates of prestigious universities is that students attending prestigious universities possess greater human capital rightfully rewarded by the labor market. However, as noted by Dale and Krueger $(2002 ; 2014)$, the prestige ascribed to the university one attended may potentially correlate with other factors in the employment process beyond human capital. The correlational studies used to test the benefits that emerge from attending a prestigious university are unable to draw a causal connection between human capital and the resulting added financial and non-financial returns (Long 2008). Prior field experiments of the labor market have not attempted to evaluate the effect of skill match — as a measure of human capital—when evaluating the impact of university prestige. Most importantly, current literature does not engage with the normative implications of the effects observed. It does not ask to what extent and under what conditions is it fair to accept disproportionate employment benefits for attendees of prestigious institutions? The paper employs logistic regression to analyze the results. I hypothesize that added labor market benefits associated with university prestige may be either a proxy for merit—as predicted by human capital theory — or more problematically, evidence of discrimination.

\section{Framework}

The effect of university prestige in the labor market may be a function of three mechanisms. First, attendees of more prestigious institutions may possess added skills that are rewarded by the labor market. This mechanism, better known as human capital 
theory (Becker 1975; Mincer 1974; Schultz 1961), also explains why attending a university yields better employment returns for graduates: universities either equip or select individuals with additional skills recognized and rewarded by the labor market. The use of human capital in the labor market—with all its limitations — is relatively aligned with meritocratic principles.

Second, the effect of university prestige in the labor market may be the result of the name of the university. This in turn may be a function of two distinct mechanisms. First, employers may use the name of the university as a signal, based on prior experience with graduates from prestigious universities. Spence (1973) designed signaling theory to explain why the presence or absence of a college degree influences labor market outcomes in conditions of information asymmetry between employers and potential employees. In the signaling model, the presence or absence of a college degree is a proxy for skills and productivity and is reinforced by feedback loops. Unlike human capital theory, signaling does not rely on actual skills and productivity, but on assumptions of productivity. Second, the prestige associated with the name of the university may lead to freely conferred deference (Henrich and Gil-White 2001; Tumin 1967) and reflect meritocratic priming (McCoy and Major 2007). Meritocratic priming conditions underprivileged individuals to justify inequality. Jost, Pelham and Carvallo (2002) illustrate that minority and disadvantaged groups tend to internalize selfperception of inferiority; this too applies to students of low-status universities. Groups with an inferiority self-perception tend to express out-group favoritism and prefer being associated with members outside of their groups, thus favoring the success of privileged outgroups. Supported by system justification theory, the authors reveal that students from high-status universities reversely manifest in-group favoritism and prefer being associated with members within their group. System justification theory suggests that 
'people consciously and unconsciously justify and perpetuate existing social arrangements' (587). Thus, individuals are likely to value other people's merit based on and consistent with the assumptions of merit made by society. Insofar as university prestige is equated to merit, employers may either defer to university prestige or choose to associate themselves with it in the hiring process. Neither signaling and meritocratic priming are consistent with a meritocratic evaluation of candidates in the labor market—particularly in fields where human capital and skills-match are essential.

Third, the effect of university prestige in the labor market may be a function of social networks. It is possible that prestigious universities offer social networks that better support graduates in the labor market. Social capital theory entails that individuals obtain jobs based on their social network and the trust they have established with people they know directly or indirectly (Bayer, Ross, and Topa 2008; Petersen, Saporta, and Seidel 2000) through practices such as sharing job specific information, learning occupation specific norms, and job referrals (Montgomery 1991).

The disproportionate labor market effects of university prestige can be explained by the three mechanisms above or their combination. It may be the case that alumni of prestigious universities have added skills that position them better in the labor market, have benefited from the prestige signal or meritocratic priming of their degrees, or have more effective social networks. The field experiment of the labor market I conducted controlled for the effects of social capital in the process of applying for jobs - as fictitious applicants do not possess it — and instead analyzed the effects of the name of the university in comparison with the role played by human capital—or matched skills. The goal of this endeavor was to observe empirically if, in the employment process, skills and ability prevail in importance over university prestige priming or signaling, or if university prestige is used to sort candidates despite or above someone's skills. 


\section{Method}

I designed and submitted fictitious applications to professional entry-level job openings in two skill-intensive sectors of the labor market: information and communication technology (IT) and accounting. I used a field experiment of the labor market (Bertrand and Mullainathan 2004; Daniel 1968; Riach and Rich 2002; 2006; Tal et al. 2009) in order to differentiate between the use of the university name and the importance of skills in the hiring process. This design gives researchers the possibility to manipulate and vary the experimental variables and to employ random assignment that allows for causal inferences (Shadish, Cook, and Campbell 2002).

Job applications were attributed to graduating students from bachelor level degrees and submitted to entry level jobs. The effect of university prestige in entry-level jobs is less likely to be moderated by the effect of work experience or further education. Both IT and accounting offer ample job openings year-round and accepted online applications. Positions in these fields often require a bachelor's degree, with a preference for degrees in related fields of study. Most importantly, both sectors require specialized skills that facilitate the design of the low and high match resumes, as an operationalization of human capital. The findings of this research cannot be generalized to less skill intensive sectors of the labor market, but such sectors do not allow for straight-forward testing of the discrimination hypothesis.

One high match resume and one low match resume were submitted to each eligible job opening. I randomly assigned the prestige condition and the sex of the applicant to each of these resumes. This assignment process also served to validate the research instrument by measuring the gap in callbacks between the resumes in the low and high match conditions, as each employer had the opportunity to revise both resumes. The gap in callbacks between high and low match application are likely not 
associated with random assignment effects, but the preference of employers for one match condition over the other.

I submitted job applications in the US, the UK, and Australia. All fictitious applicants were citizens of the countries where the experiment was conducted and they were graduating from domestic universities. The selected countries include diverse and growing labor markets, where sufficient job openings were available, where the application process operates in English, and a significant number of job openings was available online. Stratification of higher education in these countries allows for the operationalization of university prestige.

Altogether, 2,400 job applications were submitted to 1,200 country-wide job openings, meeting the power analysis requirements for multiple logistic regression. The number of applications submitted is consistent with the prior fields experiments of the labor market (Bertrand and Mullainathan 2004). Job openings were selected by conducting frequent job searches using standardized keywords on a major international job portal that operates across the three countries. In the form of a census, applications were submitted to all available entry level job openings in selected fields that met a minimum set of conditions: (1) did not require the presence of social and professional media (e.g. Linkedin), (2) did not require extensive documentation (e.g. proof of diplomas, letters of reference, names of supervisors), (3) have been posted less than 30 days prior to the application submission, and (4) no prior application has been submitted to that employer as part of this experiment (e.g. applications were submitted to 1,200 distinct employers). The majority of job postings available satisfied these criteria.

The research questions of this study were operationalized using the following statistical question: are the effects on the callback rate of applicant match and university prestige, and their interaction, constant across sex, sector, and country? I 
used SPSS to run four logistic regression models that look at comparisons across experimental conditions on callbacks as an outcome variable. The models were built using the EMMEANS subcommand in SPSS, which allows the comparison of the interaction between university prestige (non-high-ranked and high-ranked randomly assigned conditions) and match of the application (low match and high match blocked conditions).

\section{Operationalizing university prestige}

For each experimental country, one typical high-ranked university and one typical nonhigh-ranked university were selected. As such, fictitious applications were attributed to one of two selected universities in each country. In each country, the typical highranked university selected for this study has been consistently ranked between the 1100th best universities worldwide in all iterations of the (1) Academic Ranking of World Universities, (2) Times Higher Education World University Rankings, and the (3) QS World University Ranking, between 2012-2016. This ensured that the highranked institution selected is unquestionably prestigious. I also ensured that the selected university is highly ranked within its respective country and-where relevant rankings were available - for their subject. The selected high-ranked university in the US was ranked in the top 40 of the 2017 US World News and World Report National University Ranking. In the UK, the university selected was ranked among top 20 universities listed in the 2017 University League Tables. In Australia, the selected high-raked university was part of the Group of Eight. I excluded most prestigious universities in the US (Harvard, Stanford, and MIT) and the UK (Oxford and Cambridge) since some of these do not offer accounting degrees.

The typical non-high-ranked university selected in each country is still of highquality. Universities that have appeared at least once in global rankings and did not fare 
very well in national rankings were included. In the US, the selected non-high-ranked university is a university that has been globally ranked at least once but was not part of the National University Ranking of 2017 compiled by U.S. World News and World Report. In the UK, all 2017 Best Universities in the UK, compiled by Times Higher Education, were excluded. As Australia did not have an established national ranking, I simply included only Australian universities that were ranked above 400 globally. Across countries, I consulted subjects' rankings to ensure the selected institutions were not ranked highly in accounting or IT. Both the high-ranked and the non-high-ranked institution are located in the same city.

\section{Instrument design and operationalizing human capital}

I designed the fictitious resumes used as part of this study using the method designed by Bertrand and Mullainathan (2004). In step one, job descriptions from relevant job openings were centralized into a database. For each country, at least 25 job descriptions of accounting positions and 50 job description of IT positions were selected. I then coded the job descriptions into emergent themes and criteria the high-match resumes for each sector should meet, excluding criteria that were difficult to achieve for an entrylevel candidate (e.g. certificates that required several years of experience). For IT, the technical skills that were most frequently mentioned across job openings were included.

Second, real resumes were collected from various sources including LinkedIn, company employee profiles, university career services websites, and sample resumes available on recruitment websites. Using the emergent criteria from step one, the components of these resumes were coded as high match or low match. At the end of this process, I obtained a list of examples for sought after features and of less-desired features in each respective industry. I then combined these features into fictitious resumes of high and low match. High match resumes met most job description 
requirements for each labor market sector and represented a strong candidate for the sector. Conversely, low match resumes did not meet most job description requirements for a sector. The low match resumes still included comparable and potentially transferable education and work experience. The same low match resume was used for both accounting and IT positions.

The validity of the research instruments has been tested and improved by conducting two rounds of semi-structured interviews with experts in recruitment. The first round of interviews consisted of 8 interviews. The feedback collected enabled the refinements and improvement of the resumes. Following, feedback from one expert from each experimental country was sought on the revised versions of the resumes. At this point, experts agreed that (1) the high-match resumes met entry level requirements for a college graduate, (2) all resumes were believable, and (3) there was a significant gap in the match level between the low and the high match resumes. Interviewed recruiters included individuals who specialize in IT and accounting and provided fieldspecific feedback. Cover letters were created by a cover letter consultant. Appendices 13 includes anonymized examples of the resumes used in the United States.

\section{Fictitious personal data and callbacks}

Fictitious names were designed by combining common first and last names the class of 2018 using the official website of national governments. Email accounts were opened via Google mail, using an available combination of the designated names. Fictitious addresses, were chosen using Google Maps. The addresses were located in the city where the applicants' university was located. Telephone numbers were assured via Skype numbers for each country where the experiment took place. While the email accounts I created proved to be reliable in recording callbacks from employers, the Skype numbers I used as part of this experiment proved less reliable. This is because 
many callers did not attempt to leave a message and because many of the voice messages received on these phone numbers could not be heard. Overall, $45 \%$ of calls received to skype numbers remain untraced. This source of error is unlikely to affect the validity of the results, as it likely does not correlate with any of the constructs of interest in this study. It is also unlikely that the distribution of callbacks that originate from phone calls would be distinct than the distribution of callbacks received by email. This source of error is likely to lead to an underreporting in the overall callback rates to this experiment.

\section{Design limitations}

The experiment is unable to draw causal inferences about crucial aspects of the labor market such as hiring, promotion, and salary (Bertrand and Mullainathan 2004). However, information about the first stage of the recruitment process offers valuable data about discrimination patterns. The causal inferences allowed by this study are difficult to achieve with other aspect of the labor market (Bertrand and Mullainathan 2004; Daniel 1968). The first stage of the selection process functions as a gatekeeper. As the pool of candidates for further employment decision is limited by discrimination at the early stages, this type of research is warranted (Fernandez-Mateo \& King, 2011). Heckman and Siegelman (1993) challenge labor market field experiments on account that they are not double blind. As such, the researches may unconsciously design the instrument as to yield the results desired. Through the validation processwhich included 11 interviews with recruiters and human resource experts in the UK, Australia, and the US - I triangulated and improved the research instrument, thus decreasing concerns about bias. Anonymized resumes are available for consultation in Appendices 1-3. 
Due to the exclusion of uniquely prestigious universities in the US and the UK - as some of these do not offer accounting degrees - the results of this experiment may not be generalized to these institutions. The findings of this experiment should not be generalized beyond the sectors of IT and accounting, and particularly to less intensives skill sectors of the labor market.

\section{Results}

Among 2,400 applications, $276(11.5 \%)$ received callbacks. Callback rates are the percentage of applications that received a callback for one or more experimental conditions, as specified. Applications in the high match conditions —or the high human capital condition — received a higher callback rate than applications in the low matchor low human capital — condition. Overall, $19.1 \%$ of applications in the high match condition received a callback, whereas only $3.9 \%$ of applications in the low match condition received callbacks. Some variations can be found within the match condition across other experimental conditions.

High match applications from a high ranked university received a callback of $19.2 \%$, just 0.2 percentage points higher than applications from the non-high ranked condition (19.0\%). For high match applications, both male and female applicants received a $19.1 \%$ callback rate. Across fields of study, high match applications to accounting jobs received an $18.2 \%$ callback rate, and applications to IT positions received a slightly higher, $20 \%$ callback rate. Callback rates across countries for high match applications were more varied, ranging from 15\% in Australia, 17.3\% in the US, and $25 \%$ in the UK. Variations can be found within sectors of the labor market across countries and sexes. Callback rates in the high match condition vary from $9.1 \%$ for high prestige male IT applications in the US to $37.7 \%$ for high prestige female IT applications in the UK. This discrepancy is the equivalent of a little less than 1 in 10 
applications receiving callbacks versus more than 1 in 3 applications receiving callbacks (see Table 1).

[t]Table 1 near here[/t]

Four logistic regression models were conducted to test if the effect of match, prestige, and their interaction are constant across the sex, sector, and country conditions (see Table 2). In Model 1, I test the effect of prestige, match, their interaction, and sex (female and male) on callbacks. The match condition was statistically significant in predicting callbacks $(\mathrm{p}<.001)$. Applications in the high-match condition were more likely to receive a callback than applications in the low match condition. The prestige condition, the interaction between university prestige and the match condition, and the effect of sex were not statistically significant. The lack of statistical significance for sex discrimination is inconsistent with prior findings of field experiments of the labor market (Black \& Smith, 2004; Booth \& Leigh, 2010; Long, 2008; Riach \& Rich, 2006).

In Model 2, I test the effect of match, prestige, their interaction, and labor market sector (accounting and IT) on callbacks. The match of the application remained a statistically significant variable $(\mathrm{p}<.001)$, whereas the prestige of the application $(\mathrm{p}=$ $.915)$ and the interaction between university prestige and match $(p=.160)$ were not statistically significant. The labor market sector was not a statistically significant predictor of callbacks $(\mathrm{p}=.623)$.

Models 3 and 4 test the effect of university prestige, match, and country. For the purpose of these models, dummy variables were created to facilitate comparisons between countries. Model 3 uses the US as a reference country. Model 4 uses the UK as a reference country. Model 3 and 4 suggest that prestige $(p=.967)$ and the interaction between prestige and match $(\mathrm{p}=.178)$ were not statistically significant predictors of callbacks. Match remained a statistically significant predictor of callbacks $(\mathrm{p}<.001)$. 
USvAustralia was not a statistically significant predictor of callbacks $(\mathrm{p}=.422)$.

USvUK $(\mathrm{p}=.001)$ and UKvAustralia $(\mathrm{p}<.001)$ are statistically significant predictors of callbacks. This relation is explained by the fact that applications in the UK (15.6\%) received a higher callback rate than applications in the US (10\%) and Australia (8.9\%).

The analysis above suggests that callback rates are predicted by match and country. Model 1, 2, 3, 4 tested the overall effects of the match condition within each level of the prestige condition. These models indicate that the effect of the match condition was statistically significant after controlling for the effects of the prestige condition, the interaction between prestige and match, sex, labor market sector, and country $(\mathrm{p}<.001)$. Across models, the effect of the prestige condition was not statistically significant.

Across models, the odds ratio of the match condition was between $\operatorname{Exp}(B)=$ .213 and $\operatorname{Exp}(B)=.208$. The probability of receiving a callback for an applicant in the high match condition was between $78.7 \%$ and $79.2 \%$ higher than for an applicant in the low match condition. Altogether, the match of the application explains roughly $11.3 \%$ of the variability in callbacks $\left(\mathrm{R}^{2}\right.$ Nagelkerke $\left.=.113\right)$. This estimate resulted from a logistic regression testing the effect of match on callbacks $(\chi 2(1)=144.810, p<.001)$.

[t]Table 2 near here[/t]

\section{Discussion}

This research found no statistically significant effect of university prestige on callback rates from employers in skill-intensive sectors of the labor market. Instead, applications in the high skill-match — or high human capital condition-were $79 \%$ more likely to receive a callback than applicants in the low match condition. However, in practice, university prestige may matter in the labor market in other ways not captured by the conditions of this experiment. Evidence suggests that prestige matters in the hidden 
labor market and for elite jobs (Rivera, 2015). Previous field experiments of the labor market have documented a positive relation between university prestige and callbacks (Gaddis 2013; Jackson 2009). These studies have not focused on skill-intensive sectors of the labor market. They may be better positioned to indicate the effect of university prestige in less skill-intensive sectors. Prestige may matter in sectors with a mismatch between the number of applicants and the number of openings available — such as academic positions (Long, Allison, and McGinnis 1979). As such, the effects of university prestige in the labor market may become further accentuated by automation and Artificial Intelligence (David 2015). While Western countries have seen a decrease of blue color jobs due to automation and a polarization of the labor market (David and Dorn 2013), it is suspected that its effects may be extended to professional jobs, including accounting and law. The consolidation of a dual labor market may amplify the effects of prestige (Beck, Horan, and Tolbert 1980; Reich, Gordon, and Edwards 1973; Sakamoto and Chen 1991; Wial 1991).

Nevertheless, the results of this experiment provide valuable insights into the relation between skills, the name of the university attended, and the labor market, with several important implications. Employers have said recurrently that they are primarily looking for skills (Morley and Aynsley 2007; Rothwell et al. 2009). This research substantiates the importance of human capital in the labor market. At institutions of academic quality, a focus on skill building and increasing human capital may compensate for the limited academic prestige of the institution. Many universities devote extensive resources to consolidating their prestige and to advance in academic rankings (Hazelkorn 2009). Perhaps university prestige does not matter outside of being at the very top of the academic hierarchy. Higher education institutions need to take their teaching mission—and thus their social mobility mission—seriously. 
Student choice is influenced by prestige. Applications at universities in the US are influenced by changes in national rankings (Bowman and Bastedo 2009; Griffith and Rask 2007). This phenomenon is in part based on the belief that the university prestige matters in students' life outcomes — a belief supported by some of the evidence I presented throughout this research. However, the results of this study suggest that - at least in skill intensive sectors of the labor market-learning well is more important than attending a more prestigious university. Students and their parents should consider the match with their institution more broadly and not rely solely on prestige. Students should be open to considering institutional quality above prestige, especially when tuition costs differ dramatically.

Higher education research—including this present study-mirrors society at large in its disproportionate focus on elite universities. While it is important for elite universities to integrate a more diverse body of students, selective institutionsregardless of how inclusive they become-remain exclusive. If nothing else, elite universities will continue to segregate students across socially constructed merit and intelligence lines. They are not and cannot be the solution for social mobility and equality. Instead, more research and resources need to be devoted to understanding how the quality of higher education can be increased across institution types and across degrees of selectivity. Questions such as how students learn better, how post-traditional students can be better served, how degree structures and requirements can meet a more diverse student body are crucial for the mission of higher education. A line of inquiry that needs further research is how value-added approaches can be improved to measure gains in human capital and skill accumulation during college years. Education researchers have long argued that value added measures rather than outcome measures and rankings are more inclusive and fairer ways to evaluate the impact of education 
(Barnett 1992; Hanushek and Rivkin 2010; Harris 2011). However-especially at the higher education level—value added approaches remain underdeveloped and controversial. For such approaches to become reliable and accepted practices, they need to be inclusive of the multiple goals of higher education institutions and mindful of the difficulty in measuring these outcomes.

This research suggests that employers do not engage in the most overt uses of university prestige when hiring. They do not prioritize prestige above skills in skill intensive sectors of the labor market. As discrimination, prejudice, and injustice are becoming covert, evidence that reveal such practices is harder to uncover. This does not mean that inequality does not exist anymore. Instead, it means that research and evidence have shifted reality not always by correcting inequality, but by making it harder to detect. The current concepts and tools available to researchers, as well as the narrow frameworks for equity—including meritocracy—have been almost stretched to their limits. Novel approaches to understanding what constitutes an equitable society need to be devised. Some of the innovative efforts will come from developing new methods, but most likely, they will derive from new theoretical frameworks.

\section{Conclusion}

I conducted a field experiment of the labor market to better understand the effects of university prestige in the labor market. High and low match fictitious applications were submitted to 1,200 entry-level professional job openings in the field of IT and accounting, in the UK, the US, and Australia. University prestige and sex were randomly assigned to these resumes. This study brought evidence that differentiates between the effect of human capital and the effect of the prestige associated with the name of a university in the labor market. Overall, 19.1 percent of the applications in the high skills match condition and 3.9 percent of the applications in the low skills match 
condition received a callback. The callback rate varied by sector of the labor market and country. Across experimental conditions, university prestige did not predict callbacks. The results bring evidence against the importance of the name of the university attended in the labor market. Instead, the skills match of the application —or the human capital displayed by an applicant—was a statistically significant predictor of callbacks. Applications that better matched the requirements of the job opening were $79 \%$ more likely to receive a callback. Sex was not a statistically significant predictor of callbacks either. As such, this study found no evidence of prestige-based or sex-based discrimination in the hiring process in skill-intensive sectors of the labor market.

The findings of this research-while narrow in scope—support the idea that human capital matters in the labor market. This finding re-emphasizes the importance of the teaching mission of universities and should be used as further evidence that learning and skill consolidation are important. Policymakers, students, universities, researchers, and employers can all contribute towards this important goal. 


\section{References}

Arcidiacono, P., J. Kinsler, and T. Ransom. 2019. Legacy and Athlete Preferences at Harvard. No. w26316. National Bureau of Economic Research.

Barnett, R. 1992. Improving higher education: Total quality care. Bristol: Open University Press.

Bayer, P., S. L. Ross, and G. Topa. 2008. "Place of work and place of residence: Informal hiring networks and labor market outcomes." Journal of political Economy 116(6): 1150-1196.

Beck, E. M., P. M. Horan, and C. M. Tolbert. 1980. "Industrial Segmentation and Labor Market Discrimination.” Social Problems 28 (2): 113-130.

Becker, G. S. 1975. Human Capital. Chicago. University of Chicago Press.

Bertrand, M., and S. Mullainathan. 2004. "Are Emily and Greg More Employable than Lakisha and Jamal? A Field Experiment on Labor Market Discrimination." American Economic Review 94(4): 991-1013.

Black, D. A. and J. A. Smith. 2004. "How Robust is the Evidence on the Effects of College Quality? Evidence from Matching.” Journal of Econometrics 121(1/2): 99-124.

Black, D. A. and J. A. Smith. 2006. "Estimating the Returns to College Quality with Multiple Proxies for Quality.” Journal of Labor Economics 24(3): 701-728.

Booth, A. and A. Leigh. 2010. "Do Employers Discriminate by Gender? A Field Experiment in Female-Dominated Occupations.” Economics Letters 107(2): 236-238. 
Bowman, N. A. and M. N. Bastedo. 2009. "Getting on the Front Page: Organizational Reputation, Status Signals, and the Impact of US News and World Report on Student Decisions." Research in Higher Education 50(5): 415-436.

Brewer, D. J., E. R. Eide. And R. G. Ehrenberg. (1999). "Does it Pay to Attend an Elite Private College?.” Journal of Human Resources, 34(1): 104-123.

Chetty, R., J. N. Friedman, E. Saez, N. Turner, and D. Yagan. 2017. Mobility Report Cards: The Role of Colleges in Intergenerational Mobility. No. w23618. National Bureau of Economic Research.

Dale, S. B. and A. B. Krueger. 2002. "Estimating the Payoff to Attending a More Selective College: An Application of Selection on Observables and Unobservables." Quarterly Journal of Economics 117(4): 1491-1527. doi:10.1162/003355302320935089.

Dale, S. B., and A. B. Krueger. 2014. "Estimating the effects of college characteristics over the career using administrative earnings data." Journal of Human Resources 49(2): 323-358.

Daniel, W. W. 1969. Racial Siscrimination in England: Based on the PEP Report. Harmondsworth: Penguin.

David, H. 2015. "Why are There Still So Many Jobs? The History and Future of Workplace Automation.” Journal of Economic Perspectives 29(3): 3-30.

David, H. and D. Dorn. 2013. "The Growth of Low-Skill Service Jobs and the Polarization of the US Labor Market.” American Economic Review 103(5): 1553-97.

Fernandez-Mateo, I. and Z. King. 2011. Anticipatory Sorting and Gender Segregation in Temporary Employment.” Management Science 57(6): 989-1008. 
Finch, D. J., L. K. Hamilton, R. Baldwin, and M. Zehner. 2013. “An Exploratory Study of Factors Affecting Undergraduate Employability.” Education + Training 55(7): 681-704.

Gaddis, M. (2013). A Matter of Degrees. Educational Credentials and Race and Gender Discrimination in the Labor Market (Doctoral Dissertation). ProQuest Dissertations and Theses database.

Griffith, A. and K. Rask. 2007. "The Influence of the US News and World Report Collegiate Rankings on the Matriculation Decision of High-Ability Students: 1995-2004." Economics of Education Review 26(2): 244-255.

Harris, D. N. 2011. Value-Added Measures in Education: What Every Educator Needs to Know. Cambridge: Harvard Education Press.

Hazelkorn, E. 2009. "Rankings and the Battle for World-Class Excellence: Institutional Strategies and Policy Choices.” Higher Education Management \& Policy 21(1): 55-76.

Heckman J. J. and P. Siegelman. 1993. "The Urban Institute Audit Studies: Their Methods and Findings. In M. Fix \& R. J. Struyk (Eds.). Clear and convincing evidence: The measurement of discrimination in America (187-248). Washington, DC: Urban Institute.

Henrich, J. and F. J. Gil-White. 2001. "The Evolution of Prestige: Freely Conferred Deference as a Mechanism for Enhancing the Benefits of Cultural Transmission." Evolution and Human Behavior 22(3): 165-196.

Hoekstra, M. 2009. "The Effect of Attending the Flagship State University on Earnings: A Discontinuity-Based Approach.” Review of Economics \& Statistics 91(4): 717-724.

Jackson, M. 2009. "Disadvantaged Through Discrimination? The Role of Employers in Social Stratification.” British Journal of Sociology 60(4): 669-692. 
Jost, J. T., B. W. Pelham, and M. R. Carvallo. 2002. "Non-Conscious Forms of System Justification: Implicit and Behavioral Preferences for Higher Status Groups.” Journal of Experimental Social Psychology 38(6): 586-602.

Long, M. C. 2008. "College Quality and Early Adult Outcomes.” Economics of Education Review 27(5): 588-602. doi:10.1016/j.econedurev.2007.04.004

Long, M. C. 2010. "Changes in the Returns to Education and College Quality. Economics of Education Review 29(3): 338-347. doi:10.1016/j.econedurev.2009.10.005

Long, J. S., P. D. Allison, and R. McGinnis. 1979. "Entrance into the Academic Career." American Sociological Review 44(5): 816-830.

McCoy, S. K. and B. Major. 2007. "Priming Meritocracy and the Psychological Justification of Inequality." Journal of Experimental Social Psychology 43: 341351.

McKinley, J., and J. Brayboy. 2004. "Hiding in the Ivy: American Indian Students and Visibility in Elite Educational Settings." Harvard Educational Review 74(2): 125-152.

Mincer, J. 1974. Schooling, Experience and Earnings. New York: Columbia University Press.

Monks, J. 2000. "The Returns to Individual and College Characteristics. Evidence from the National Longitudinal Survey of Youth." Economics of Education Review 19(3): 279-289.

Montgomery, J. D. 1991. Social Networks and Labor-Market Outcomes: Toward an Economic Analysis. The American Economic Review 81(5): 1408-1418.

Morley, L. and S. Aynsley. 2007. "Employers, Quality and Standards in Higher Education: Shared Values and Vocabularies or Elitism and Inequalities?." 
Higher Education Quarterly 61(3): 229-249. doi:10.1111/j.1468-

2273.2007.00353.x.

Posselt, J. 2016. Inside Graduate Admissions. Merit, Diversity, and Faculty

Gatekeeping. Cambridge: Harvard University Press.

Petersen, T., I. Saporta, and M. L. Seidel. 2000. "Offering a Job: Meritocracy and Social Networks.” American Journal of Sociology 106(3): 763-816.

Reich, M., D. M. Gordon, and R. C. Edwards. 1973. "A Theory of Labor Market Segmentation." The American Economic Review 63(2): 359-365.

Riach, P. A. and J. Rich. 2002. "Field Experiments of Discrimination in the Market Place.” Economic Journal 112(483): 480-518.

Riach, P. A. and J. Rich. 2006. “An Experimental Investigation of Sexual Discrimination in Hiring in the English Labor Market." Advances in Economic Analysis \& Policy 5(2).

Rivera, L. A. 2015. Pedigree. How Elite Students Get Elite Jobs. Princeton: Princeton University Press.

Roksa, J. 2011. "Differentiation and Work: Inequality in Degree Attainment in US Higher Education.” Higher Education 61(3): 293-308.

Rothwell, A., S. Jewell, and M. Hardie. 2009. "Self-Perceived Employability: Investigating the Responses of Post-Graduate Students." Journal of Vocational Behavior 75(2): 152-161. doi:10.1016/j.jvb.2009.05.002.

Sakamoto, A. and M. D. Chen. 1991. "Inequality and Attainment in a Dual Labor Market." American Sociological Review 56(3): 295-308.

Schultz, T. W. 1961. "Investment in Human Capital." American Economic Review 51(1): 1-17. 
Shadish, W. R., T. D., Cook, and D. T. Campbell. 2002. Experimental and QuasiExperimental Designs for Generalized Causal Inference. Houghton: Mifflin and Company.

Spence, M. 1973. “Job Market Signaling.” The Quarterly Journal of Economics 87(3): 355-374.

Tal, A., G. Moran, D. Rooth, and M. Bendick. 2009. “Using Situation Testing to Document Employment Discrimination Against Persons with Psychiatric Disabilities." Employee Relations Law Journal 35(3): 40-60.

Tett, L. 2004. Mature Working-Class Students in an 'Elite' University: Discourses of Risk, Choice and Exclusion. Studies in the Education of Adults 36(2): 252-264.

Tumin, M. T. 1967. Social Stratification. The Forms and Functions of Inequality. Englewood Cliffs: Prentice-Hall.

Wial, H. 1991. "Getting a Good Job: Mobility in a Segmented Labor Market." Industrial Relations 30(3): 396-416.

Table 1. Callback rate breakdown by match condition

\begin{tabular}{lcc}
\hline \multicolumn{1}{c}{ Experimental condition } & $\begin{array}{c}\text { Callback rate } \\
\text { high match applications }\end{array}$ & $\begin{array}{c}\text { Callback rate } \\
\text { low match applications }\end{array}$ \\
\hline Overall & $19.1 \%$ & $3.9 \%$ \\
High-ranked & $19.2 \%$ & $4.8 \%$ \\
Non-high ranked & $19.0 \%$ & $3.0 \%$ \\
Female & $19.1 \%$ & $5.0 \%$ \\
Male & $19.1 \%$ & $2.8 \%$ \\
Accounting & $18.2 \%$ & $4.2 \%$ \\
IT & $20.0 \%$ & $3.7 \%$ \\
United Kingdom & $25.0 \%$ & $6.3 \%$ \\
United States & $17.3 \%$ & $2.8 \%$ \\
Australia & $15.0 \%$ & $2.8 \%$ \\
UK x Accounting & $16.1 \%$ & $5.0 \%$ \\
UK x IT & $36.75 \%$ & $7.5 \%$ \\
US x Accounting & $23.0 \%$ & $4.0 \%$ \\
US x IT & $11.5 \%$ & $1.5 \%$ \\
Australia x Accounting & $15.5 \%$ & $3.5 \%$ \\
Australia x IT & $14.5 \%$ & $2.0 \%$ \\
\hline
\end{tabular}


Table 2. Logistic regression table on effect of prestige, match, and their interaction on callbacks, while controlling for sex, sector of the labor market, and country

\begin{tabular}{|c|c|c|c|c|c|c|c|c|c|c|c|c|}
\hline & \multicolumn{3}{|c|}{ Model 1} & \multicolumn{3}{|c|}{ Model 2} & \multicolumn{3}{|c|}{ Model 3} & \multicolumn{3}{|c|}{ Model 4} \\
\hline & B & $\mathrm{SE}$ & $\operatorname{Exp}(B)$ & B & $\mathrm{SE}$ & $\operatorname{Exp}(B)$ & B & $\mathrm{SE}$ & $\operatorname{Exp}(B)$ & B & $\mathrm{SE}$ & $\operatorname{Exp}(B)$ \\
\hline Intercept & $-1.489 *$ & $.123^{*}$ & $.226^{*}$ & $-1.469 *$ & $.125^{*}$ & $.230 *$ & $-1.206^{*}$ & $.217 *$ & $.299 *$ & $-2.280^{*}$ & $.219 *$ & $.803^{*}$ \\
\hline Match condition & $-1.552 *$ & $.217 *$ & $.212 *$ & $-1.545^{*}$ & $.217 *$ & $.213 *$ & $-1.569 *$ & $.218^{*}$ & $.208 *$ & $-1.569 *$ & $.218 *$ & $.208 *$ \\
\hline Prestige condition & -.018 & .147 & 1.018 & -.016 & .147 & .984 & -.006 & .148 & .994 & -.006 & .148 & .994 \\
\hline Match x Prestige & -.473 & .339 & .623 & -.477 & .339 & .620 & -.558 & .340 & .572 & -.458 & .340 & .632 \\
\hline Sex & .110 & .132 & 1.116 & & & & & & & & & \\
\hline $\begin{array}{l}\text { Labor market } \\
\text { sector }\end{array}$ & & & & .65 & .132 & 1.915 & & & & & & \\
\hline USvAustralia & & & & & & & .143 & .176 & 1.153 & & & \\
\hline USvUK & & & & & & & $-.537 *$ & $.158 *$ & $.584 *$ & & & \\
\hline UKvAustralia & & & & & & & & & & $.681 *$ & $.163 *$ & $1.976^{*}$ \\
\hline UKvUS & & & & & & & & & & $.537 *$ & $.158 *$ & $1.711^{*}$ \\
\hline Deviance & & $3.567(3)$ & & & $.392(3)$ & & & $754(6)$ & & & $.754(6)$ & \\
\hline $\begin{array}{l}* \text { Significant at } \\
\text { Model 1: } \chi 2(4) \\
\text { Model 2: } \chi 2(4) \\
\text { Model 3: } \chi 2(5) \\
\text { Model 4: } \chi 2(5)\end{array}$ & $\begin{array}{l}.001 \text { signi } \\
49.701, \mathrm{p}< \\
49.250, \mathrm{p}< \\
59.797, \mathrm{p}< \\
59.797, \mathrm{p}<\end{array}$ & $\begin{array}{l}\text { ance level } \\
01 \\
01 \\
01\end{array}$ & & & & & & & & & & \\
\hline
\end{tabular}


Appendix 1. High match resume for IT applications in the US, fictitious male applicant

\section{Daniel Smith}

Email: smith.daniel.jack@gmail.com, Telephone: 3478095513

\section{Career Objective}

College student nearing completion seeking to leverage exceptional IT skills and academic knowledge to gain entry-level software development position at your firm. Dedicated, competent, and detailoriented individual with excellent communication skills and the capacity to go beyond what is expected to achieve company goals.

\section{EdUCATIONAL BACKGROUND}

(Name of University)

(City)

Bachelor of Science in Information Systems Management

Class of 2018

- GPA 3.56

- Relevant Coursework: Introduction to Cloud Computing; HTML Programming; Javascript Programming; Design and Programming for the Web; Database Administration; Information Security Management

\section{Specialized certifications}

- Comptia A+

- ITIL (v3)

May 2017

September 2017

Professional Experience

(Name of Company)

Software Engineering Intern

(City)

- Design and develop automated trading software for backtesting historical trading data in Java platform

- Organize and facilitate Agile and Scrum meetings, which includes Sprint Planning, Daily Scrums or Standups, Sprint Check-In, Sprint Review and Retrospective

- Develop, analyze, and present results through workshops to all levels of management on topics ranging from employee selection to employee wellness

- Give recurring presentations on work progress to $10+$ colleagues and supervisors

(Name of Company)

(City)

Software Engineering Intern

May 2016 - August 2016

- Performed entry level programming, debugging, development and GUI design of Windows Applications via Windows Visual Studio Development Environment

- Architected and designed enterprise applications for policies, claims, general ledger, and agency administration using test-driven development in Ruby on Rails, JQuery, HTML, and CSS

- Created C\#.Net Windows Forms application to begin converting the Open Source text to SQL friendly input to get data into a SQL database on a centralized server

- Conducted in person and virtual company tours for prospective clients

\section{Software and Programming Skills}

- Windows, Linux, iOS, .Net, Ruby on Rails, Agile, Oracle, Visual Studio, Microsoft Office, Scrum

- C\#, Java, C++, JQuery, Javascript, CSS, HTML, SQL 
Appendix 2. High match resume for accounting applications in the US, female applicant

\section{ASHLEY JOHNSON}

Email: ashley.j.johnson.mail@gmail.com, Telephone: 3478095513

\section{Career Objective}

College student nearing completion seeking to leverage exceptional accounting skills and academic knowledge to gain entry-level accounting position at your firm. Dedicated, competent, and detailoriented individual with excellent communication and team-work skills and the capacity to go beyond what is expected to achieve company goals.

\section{EdUCATIONAL BACKGROUND}

(Name of University)

(City)

Bachelor of Science in Business

Class of 2018

Concentration in Accounting, GPA 3.56

- Relevant Coursework: Taxation: Individual and Business Income; Auditing; International Reporting and Analysis; Forensic Accounting and Financial Statement Fraud

\section{Professional Experience}

(Name of Company)

(City)

One of the largest independent public accounting and advisory service firms in the nation, with offices in major business markets throughout the U.S. and abroad

\section{Accounting Assistant Intern}

January 2017 - Present

- Manage accounts payable, prepare journal entries, set up and maintain accounts, process payments, and prepare reports for management

- Manage monthly bank reconciliation of approximately $\$ 100,000$

- Assist in the preparation of State and Federal taxes, for individuals, businesses, and small-sized corporations utilizing forms 1040, 1041, 1120, 1120S, 1065

- Advise 20+ international clients on wide set of tax matters and resolved matters in a quick and effective manner

- Conduct in-person and virtual company tours for prospective clients and retained $10+$ clients

(Name of Company)

(City)

Established in (year), the company offers services in the field of accounting, tax, management advisory, and financial services

\section{Accounting Intern}

May 2016 - September 2016

- Entered invoices into accounts payable approval system for routing to project managers

- Collected and compiled client financial data, entered information into QuickBooks or MYOB and assigned appropriate journal accounts for accurate accounting of income and expenses

- Conducted ad hoc financial analysis under senior accountant supervision

- Ensured all departmental invoices were correctly coded and documented for payment within the period. Cooperated with vendors to ensure all invoices were paid on a timely basis

- Gave recurring presentations on work progress to $10+$ colleagues and supervisors

\section{TeChNical Skills}

- $\quad$ QuickBooks certified, MYOB, Xero, HandiSoft, ERP package (Oracle, Dynamics AX), SAP, SQL, Excel, MS Office 
Appendix 3. Low match resume for IT applications in the US, male applicant

\section{Matthew Jones}

jones.matthew.mail@gmail.com // 3478096760

\section{Career Objective}

Current student nearing completion with extensive teaching and customer service experience seeking entry-level job in the accounting industry. Team player with excellent critical thinking skills and the ability to identify alternative solutions to problems.

\section{Education}

(Name of University)

(City)

Bachelor of Science in Biology

2018

Major in Biology; Minor in Digital Forensics

GPA: 3.5

- Courses: Calculus, Biological Applications; Bio-Statistics; Introduction to Information Security; Fundamental of Accounting

\section{Professional Experience}

Self-employed

(City)

Mathematics and Biology Tutor

2016 - Present

- Specialize as an individual tutor by simplifying math and biology concepts while coaching high school students to think critically and to solve problems

- Improve students' performance on SAT by $10 \%$

- Prepare daily lesson plans for activities

- Help struggling students improve their critical thinking and problem-solving skills

- Cultivate a fun and interesting learning environment which encourages questions and discussions

(Name of Company)

- Promoted business development and increased customer loyalty by $6 \%$ through demonstrating excellent follow-through with customers and management throughout all phases of the insurance claims process

- Named customer service officer of the month two times

- Processed payments up to $\$ 50,000$ and updated systems of record to ensure that account maintenance is current and accurate

- Prepared reports, Power Point presentations, and Excel spreadsheets weekly and monthly for executive management for concise and easy resolution

- Contributed to teams made up of web designers, programmers, and customer service representatives

\section{Software skills}

- R, SageMath, MathLab, MEGA, CAINE, MS Office 